\title{
The burden of avoidable emergency gynaecological admissions; a service evaluation audit
}

\author{
de Lanerolle $\mathrm{MI}^{1}$, Jayawardane DBIA ${ }^{2}$
}

\section{INTRODUCTION}

Acute gynaecological problems represent a large number of medical help seeking events among women of reproductive age. The number of such episodes is thought to exceed the numbers of elective admissions. Some of the women who present with acute complaints may be managed in the emergency department while only the others will require admission to the gnaecology ward. Well established emergency departments are capable of carrying out a basic evaluation of the presenting problem and decide which patients require urgent specialized care and they will be channeled to the emergency gynaecological services. Others with semi-urgent presentations and those that can be seen in a nonurgent manner would be sent home with a management plan.

The reasons for unplanned admissions in gynaecology department include early pregnancy complications, menstrual abnormalities, unplanned admissions for elective procedures and other miscellaneous gynaecological conditions such as pelvic inflammatory disease and ovarian cyst accidents. While some of these can be managed through non-urgent pathways, it is important that conditions that require urgent attention are not missed. In the Sri Lankan health system model, the outpatient departments are not equipped to screen or manage acute gynaecological admissions.

\footnotetext{
Registrar in Emergency Medicine, The National Hospital of Sri Lanka

2 Specialist Obstetrician and Gynaecologist, Department of Obstetrics and Gynaecology, University of Colombo, Sri Lanka
}

\section{Correspondence: Dr. M I de Lanerolle}

E-mail: indikalena@yahoo.com

Competing interests: None
Therefore, all women who present to the emergency department are admitted to the gynaecology ward for further management. These patients contribute to a considerable proportion of bed occupancy and use other resources in the gynaecology department.

With increasing demands for hospital beds it is important that we minimize the unnecessary hospital admissions. This will require active involvement of trained doctors to ensure women receive the best possible treatment while being less demanding on the system. Previous studies have attempted to assess the effects of establishment of an acute gynaecological unit to manage acute gynaecological presentations. Such an approach has shown to result in improved patient care, better treatment outcome and better patient satisfaction while being more cost effective $^{1}$. In order to assess the usefulness of such a setting in our local health system, we carried out a service evaluation audit to determine the proportion of acute gynaecological patients that can be managed without admission to the hospital.

The objectives of this study were to identify the type of presentations in unplanned gynaecological admissions and to determine the proportion of patients that could be managed through non-urgent care pathways.

\section{METHODS}

All patients who got had unplanned admissions to the professorial gynaecology ward of the National Hospital of Sri Lanka between the 1st of February and 30th of April 2014 were included in the study. A retrospective analysis of the medical notes was carried out. The medical documentation at the time of admission was reviewed to understand the clinical presentation and the documentation on the day of the discharge was studied to identify the final diagnosis. A predesigned proforma was used for data collection.

A consultant gynaecologist was asked to comment if the woman could have been managed as an outpatient, if an emergency treatment facility was available to screen and evaluate patients on presentation. The initial presentation, clinical findings and the inward management (both investigations and treatment given) were taken into consideration prior to making judgments on the suitability for nonurgent care pathway management. For the purpose of the study the presentations were categorized into four main groups as early pregnancy complications, menstrual disorders, unplanned admissions for elective procedures and other miscellaneous acute gynecological conditions. The data collected was analyzed according to the type presentation and the suitability for non-urgent care pathway management. The data is presented in numbers and as percentages.

\section{RESULTS}

There were 294 unplanned admissions to the ward during the three-month study period. Early pregnancy complications were the commonest cause for such admissions $(n=125$, $42.5 \%$ ) followed by menstrual abnormalities $\quad(n=54, \quad 18.37 \%)$, unplanned admissions for elective procedures $(n=89,30.27 \%)$ and miscellaneous acute gyanecological problems $\quad(n=26, \quad 8.84 \%)$. The distribution of the study population according to the type or presentation is shown in figure 1 . 
Figure 1. The distribution of the study population according to reason for admission

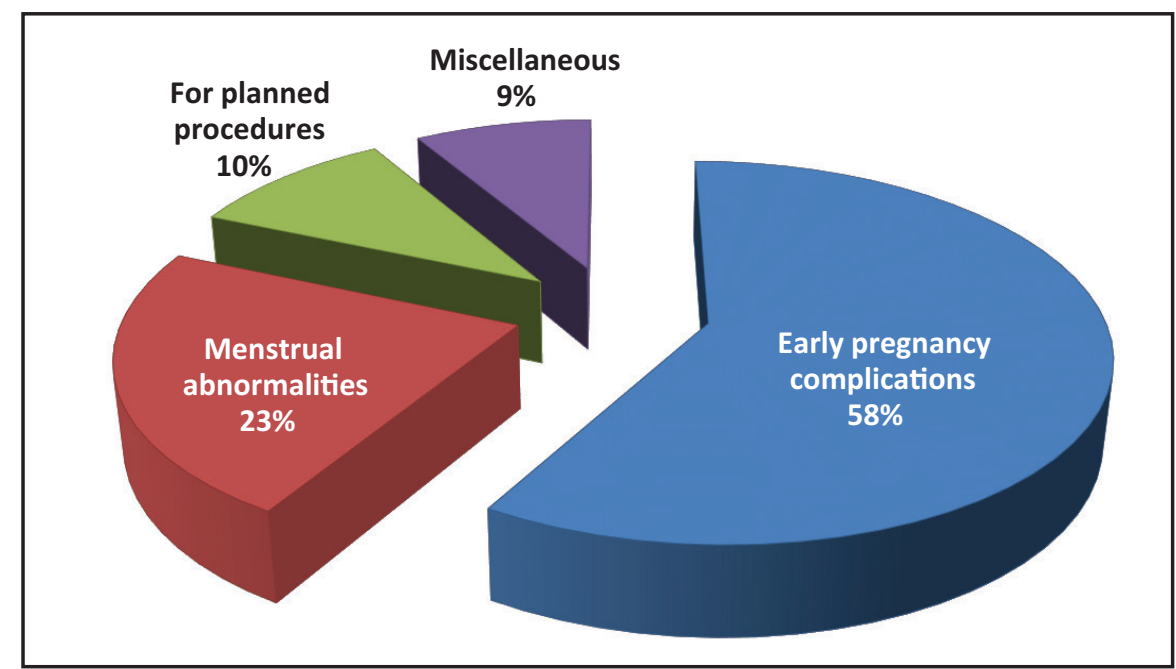

Miscarriage was the commonest cause for admission among patients with early pregnancy complications $(n=68,54.4 \%)$ and they presented with threatened miscarriage $(n=46)$, incomplete miscarriage $(\mathrm{n}=10)$, missed miscarriage $(n=6)$ and complete miscarriage $(n=5)$. One patient presented with miscarriage complicated by sepsis. Excessive vomiting in early pregnancy was the cause for presentation in 16 patients $(n=12.8 \%)$. Raised blood pressure, diabetes mellitus, vulval pain and gastroeneteritis in early pregnancy were the cause in 19 admissions. There were $22(17.6 \%)$ patients who presented with abdominal pain in early pregnancy. The reason for the pain was an ectopic pregnancy in twelve patients, urinary tract infections in 5 while no pathology was found in five patients. Among the women who presented with menstrual abnormalities, 37 (68.5\%) were in the perimenopausal age group. Acute abdominal pain related to either ovarian cysts, pelvic inflammatory disease, urinary tract infection or fibroid uterus was the leading cause
( $\mathrm{n}=18,69.2 \%$ ) among patients with miscellaneous gynaecological causes. The other miscellaneous causes included vaginal candidiasis, urine retention, sexual abuse, Bartholin's cysts or abscesses. There were 89 patients whose admissions was unplanned but on a request by a gynaecologist, commonly for an elective procedure. This group was not analyzed further since they do not come under the care of an emergency department.

Analysis of the clinical presentation and the final diagnosis to evaluate their suitability for outpatient management in non-urgent care pathways revealed that $54.6 \%(n=112)$ of the unplanned admissions could have been avoided by an emergency department capable of gynaecological assessment. This included $60 \%$ (75 out of 125) women with early pregnancy problems, $48.1 \%$ (26 of 54 ) with menstrual problems and $42.3 \%$ (11 of 26) with miscellaneous acute gynaecology admissions. The proportion of women that were suitable for non-urgent care pathways is shown in figure 2 .

Figure 2. The proportion of women that were suitable for non-urgent care pathways

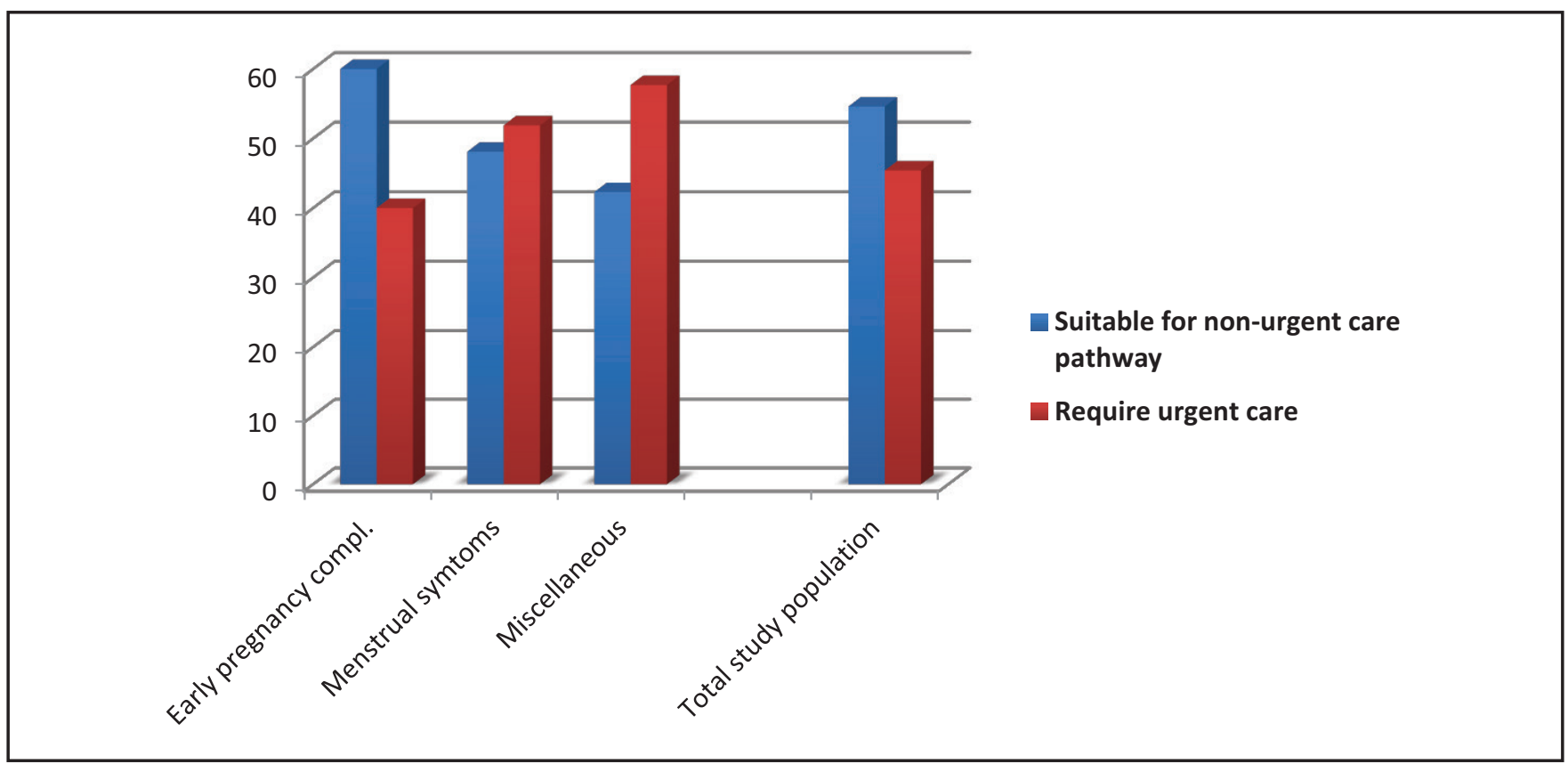




\section{DISCUSSION}

This service evaluation audit was aimed at improving our understanding of the unplanned gynaecological admissions in order to develop health care policies to optimize the usage of health care resources. Outpatient management is desired in many instances since it is more cost effective and is associated with better patient satisfaction.

As expected, most unplanned admissions to the gynaecology ward were with early pregnancy problems. Among them most were suitable for outpatient management in a nonurgent care pathway. Such facilities are in place in other health care systems and for such as system to be effective it should include trained staff in the emergency department and a dedicated early pregnancy assessment unit where a trained person can review the patients in a non-urgent manner ${ }^{2}$. Establishment of such services have been recommended by national institute of health and clinical excellence $\mathrm{n}$ UK as it is associated with less gynaecology bed occupancy and better patient satisfaction ${ }^{3}$. Evaluation of other clinical presentations will require some gynaecological training by the emergency department staff. If such training is not feasible, input of the gynaecological team in management of the gynaecological patients in the emergency department can provide the required technical expertise.

The findings of this study were similar to many other studies that were done in other parts of the world ${ }^{4-6}$. To our knowledge, this is the first time this has been reported in Sri Lanka. These findings are timely as the Ministry of Health in Sri Lanka is in the process of establishing emergency units in the government hospitals. Infrastructure development and training in emergency medicine has already commenced. Similar audits in other fields also would provide important baseline data that can be used to design services in the emergency department.

\section{REFERENCES}

1. Kumar V, Gupta J, Shehmar M. Analysis of an Innovative One-stop, Hospitalbased, Outpatient Acute Gynaecology Clinic Model for Taking the Service to Community. Journal of Family planning and Reproductive health care. 2013;39(4):292-294
2. Royal College of Obstetricians and Gynaecologists. Good Practice advice No. 9: Gynaecology: Emergency Services Standards of Practice and Service Organization. 2009, RCOG. London.

3. National Institute of Health and Clinical Excellence. Clinical Guideline on ectopic pregnancy and miscarriage. 2012. National Institute of Health and Clinical Excellence, Manchester, UK.

4. Wong SF, Lk Yeo E, Hy Tse L. An Audit of Emergency Gynaecological Admission in a Regional Hospital. HongKong Journal of Obstetrics, Gynaecology and Midwifery. 2000;1(81):85

5. Wamwana EB, Ndavi PM, Gichangi PB, Karanja JG, Muia EG, Jaldesa GW. Socio-demographic characteristics of patients admitted with gynaecological emergency conditions at the provincial general hospital, Kakamega, Kenya. East African Medical Journal 2006; 83(12):659-65

6. Bhide A, Osborne A, Hutt R. Acute Gynaecology Admissions Audit- Royal Surrey County Hospital, UK. Accessed on 10th January 2015 at http:// epostersonline.s3.amazonaws.com/ rcog2011/rcog2011.156040f.NORMAL. pdf. 